\title{
Importance of Applying Statistical Sampling to Increase Confidence in Financial Statements
}

\author{
Filipe Mahaluça*, Gilda Chissengue, Jerónimo Uamba, Isvera Pereira, Emidio Mabjaia, Alfeu Vilanculos \\ Higher Institute of Accounting and Audit of Mozambique, Maputo, Maputo, Mozambique
}

\begin{abstract}
Background: Sampling is an important tool considered viable and indispensable for the execution of auditing procedures, since they provide scientific evidence about the universe as a whole and can be used in all types of auditing, becoming tools of great interest, which is why we chose this study. The present study aims to analyze the importance of the application of statistical sampling in increasing the confidence of the financial statements.

Methods: This was a descriptive, quantitative bibliographic study of secondary data that has as a source of research filtering in the search sites Wiley Online Library, Science Direct, American Accounting Association and Google Scholar, using as descriptors: financial audit, statistical sampling, audit sampling, financial demonstrations and accounting.

Results: Of the 40 articles analyzed, 30\% are from the Asian region, 28\% from North America, 18\% from Europe, 15\% from Latin America and 10\% from Africa. Convenience sampling was the most predominant with 57.5\%. All articles published by African authors used sampling for convenience. Statistical sampling was more prevalent in North American and European articles. The Chi-Square test shows the lack of a provenance relationship between the preference for the type of sampling and the region.

Conclusions: The use of statistical sampling does not relegate the auditor's judgment to the background but it allows the risk of sampling to be measured. Through statistical tools, the auditor can specify the audit risk he or she wants to run, and the sample size is a reflection of risk.
\end{abstract}

Keywords: Earning persistence; Forecast ability; Firm performance; Economic value added

\section{INTRODUCTION}

Financial auditing focuses on financial statements and it is considered effective when it is intended to prevent omission errors, commissioned errors and errors of principle [1,2].

Audit procedures are the set of techniques that enable the auditor to obtain sufficient or adequate evidence or evidence to substantiate his or her opinion on the audited financial statements [3]. Thus, the main purpose of an audit is to increase the degree of confidence of the recipients of the financial statements [4].

The financial statements are prepared and disclosed in accordance with the Accounting and Financial Reporting Standards and the legislation in force at the date of preparation. The financial audits, mandatory in some cases, certify that the financial statements show the true economic, financial and equity situation of the company [5].
The audited financial statements give companies greater credibility, giving users greater security in decision making and avoiding concerns about possible data manipulation [6]. The professional activity carried out by the auditor implies a great deal of responsibility, and therefore requires total independence and neutrality in relation to the audited object, allowing the audit work to be the product of impartial analysis and, therefore, reliable [7].

In auditing it is necessary to verify and test the transactions occurring in the company, analyze and test documents, books, internal control systems and financial statements [8]. These procedures cover substantive tests and control tests. Control tests are used to verify replace with if the internal control system established by the company is observed and complied with. Substantive tests are intended to provide sufficient evidence of the accuracy of the transactions and balances of the financial statements [9].

Given the diversity of documents required for the auditor's

\footnotetext{
${ }^{*}$ Correspondence to: Filipe Mahaluca, Higher Institute of Accounting and Audit of Mozambique, Maputo, Mozambique, Tel: +258-848407234; E-mail: filipe. mahaluca@iscam.ac.mz
}

Received: March 29, 2019; Accepted: April 26, 2019; Published: May 03, 2019

Citation: Mahaluça F, Chissengue G, Uamba J, Pereira I, Mabjaia E, Vilanculos A (2019) Importance of Applying Statistical Sampling to Increase Confidence in Financial Statements. Int J Account Res 7:198. doi: 10.35248/2472-114X.19.7.198

Copyright: (C) 2019 Mahaluça F, et al. This is an open-access article distributed under the terms of the Creative Commons Attribution License, which permits unrestricted use, distribution, and reproduction in any medium, provided the original author and source are credited. 
assessment, it is unfeasible to examine all records because of the time and cost factors and the quality of work performed by the auditor. Thus, sampling is an indispensable technique for use by the auditor, particularly when faced with a population of difficult analysis, due to its size, and intends to conclude on the whole universe of transactions to be examined and tested [10].

Sampling is an important tool considered viable and indispensable for the execution of auditing procedures, since they provide scientific evidence about the universe as a whole and can be used in all types of auditing, becoming tools of great interest, which is why we chose this study.

At the global level, there are very few studies related to financial auditing that address the importance of the applicability of sampling. In Mozambique, although sampling techniques are known by accountants and auditors during their training, the relevance of these in their application in financial auditing is almost unknown.

Considering the above, the present study aims to analyze the importance of the application of statistical sampling in increasing the confidence of the financial statements.

\section{LITERATURE REVIEW}

\section{Audit sampling}

The auditor shall obtain appropriate and adequate audit evidence through inspections, observations, inquiries, confirmations, calculations and analytical procedures, the performance and conclusions of which shall be adequately documented in order to support his opinion [11]. That is, the auditor should obtain evidence of his work through specific methods and techniques, known as audit procedures, ranging from work to work to fit the circumstances they encounter [12].

In the application of audit procedures, audit evidence is obtained through substantive testing and control tests [13], Where control tests, which include an analysis of the accounting system and the internal control system, are not adequate, substantive procedures shall be applied by means of detail tests for each class of transactions, account balances and disclosures, and the analytical procedures are applied by analyzing the relationships between financial and nonfinancial data [14].

Since sampling is a technique used by the auditor, audit sampling consists of the application to less than $100 \%$ of the items of a relevant population in auditing, so that all sample units have the possibility of being selected in order to provide the auditor a reasonable basis upon which he draws conclusions about the entire population [15]. The auditor can opt for the full evaluation of all the operations carried out by the company, but being a company with a considerable number of movements and weighing the costs and the time in which the auditor would need to analyze all operations, it is undoubtedly essential to apply sampling [16].

The selected sample should take into account specific items, that is, the auditor should include documents with high values in the sample, all items from a certain amount, indispensable items to obtain information and items to test the control activities.

In the audit engagement, the auditor incurs a sampling risk that occurs when the auditor issues an erroneous opinion based on the sample collected [17].

\section{Sampling in substantive tests}

The substantive tests are applied to verify and evaluate the monetary amounts involved in group and account balances. Sampling in substantive tests or sampling of variables is intended to estimate a monetary total of a population or the monetary value of errors in a population [18].

The auditor should rely on the cost/benefit check to accept some doubts when the cost of checking $100 \%$ of the population items becomes greater than coming to erroneous opinion by examining only one sample. In substantive tests, in the application of sampling, the risk of the first species, which is the risk of incorrect rejection, involves the efficiency of the audit. The second type risk, which is the risk of incorrect acceptance, addresses the effectiveness of the audit [19].

Statistical sampling and convenience sampling in substantive tests: The sampling process can be used in the audit work in two processes: Statistical sampling and convenience sampling. Probabilistic or random sampling is one that is supported by mathematical methods based on the calculation of probabilities [15]. Conversely, in convenience sampling, the auditor uses subjectivity, based on judgment, judgment in own criteria and more specifically in his capacity and professional experience [20].

In audit the technique of sampling for convenience is more used than random sampling [10]. Regardless of the technique used, the auditor should always use four different phases:

- Determine the appropriate sample size.

- Select or identify the sample.

- Apply appropriate audit procedures to selected items.

- Evaluate the results of the sample.

\section{Sample determination}

When selecting the elements of a population, one must consider whether this sample is representative of the universe [15]. Regardless of the sampling technique chosen, the auditor should be aware of different factors influencing sample size:

- Population dispersal.

- Level of risk you are willing to accept.

- Maximum tolerable error.

- Population expectancy.

- Accuracy.

- Confidence level.

- Population size.

\section{Sample selection}

A random sample exists when all elements of a population are equally likely to be selected. When the auditor makes a selection of the sample, he must take into account its representativeness, because if it is not representative, that is, if it is skewed, the conclusions that will be obtained about the population in question are not valid [10].

The concept of a random sample requires that the selection of elements is not distorted or influenced, either consciously or unconsciously by the auditor, and should use processes such as 
random number tables, random number generator (computer technique), systematic selection, random selection and selection in blocks $[10,15]$.

\section{Evaluation of sample results}

The auditor should evaluate the results of the sample to see if what he got is in agreement with what he hoped to obtain. If it is not compatible, you will have to deepen your evaluation. If the auditor finds that his preliminary assessment of population characteristics needs to be reviewed, he has the option of requesting help from management to investigate potential errors by making any adjustments he deems necessary [21].

He can modify the planned audit procedures and have to mention the change in the audit report.

If it is found that all the elements of the sample are correctly recorded and comply with all the requirements defined by the auditor in the previously prepared programs, then it may be concluded that although there may be errors, they are not materially relevant and should validate the population in question.

\section{Sampling in compliance tests}

The sampling in the compliance tests is intended to verify the rate of deviations applied to a particular type of control. Its application is not related to monetary values, but to the application of necessary procedures that will serve as a basis for the valuation and measurement of transactions. Therefore, it is necessary to have a documentary evidence trail regarding the control procedure being tested [19].

In compliance tests, to perform statistical sampling, or sampling of attributes, as well as in any form of sampling, it is necessary to carry out a planning that serves as a guide in the course of the auditor's tasks, so that he can successfully complete his work.

\section{Risk of sampling}

The risk of sampling assumes that if the total population passed through the same procedure used in the sample population, the auditor should have another conclusion. In other words, the show was not properly chosen because it does not reflect the reality of the population as a whole.

The auditor faces the risk of sampling in two cases: in the control test and in verification procedures. In the control test, there is a risk of over-evaluation or under-assessment of reliability, that is, in which case the sample result would apparently not provide reliable support for the assessment of the population as a whole, which in fact does not occur. Thus, the reliability of the sample is underestimated [10].

In the verification procedures, there is the problem of the risk of incorrect rejection and the risk of incorrect acceptance. The problem of the risk of incorrect rejection occurs when the result of the sample leads one to believe that the transaction data are materially distorted, while in fact they are not.

\section{MATERIAL AND METHODS}

It is a descriptive, quantitative, bibliographic study of secondary data that has as a source of research filtering in the search sites 6 and Google Scholar, using as descriptors: financial audit, statistical sampling, audit sampling, financial demonstrations and accounting.

The inclusion criteria used for the search were:

- Articles published between the years 2010 and 2018. This time cut was used to select the most recent works, since the use of sampling techniques in auditing has increased considerably in recent years; and

- Texts in full that specifically addressed the subject under study.

Exclusion criteria were:

- Theses, thesis chapters, books, book chapters, annals of conferences or conferences, technical and scientific reports, and ministerial documents.

At the end of the bibliographical survey, 40 articles were actually used, selected according to the quality and relevance with the proposed theme.

For the data analysis, the articles were distributed as per region, using the Chi-square test with a confidence level of $95 \%$ to establish the relationship between them. All $p$-value below $5 \%$ were considered significant.

\section{RESULTS}

As shown in Figure 1, of the 40 articles analyzed, 30\% are from the Asian region, 28\% from North America, 18\% from Europe, 15\% from Latin America and 10\% from Africa. Of the articles analyzed,

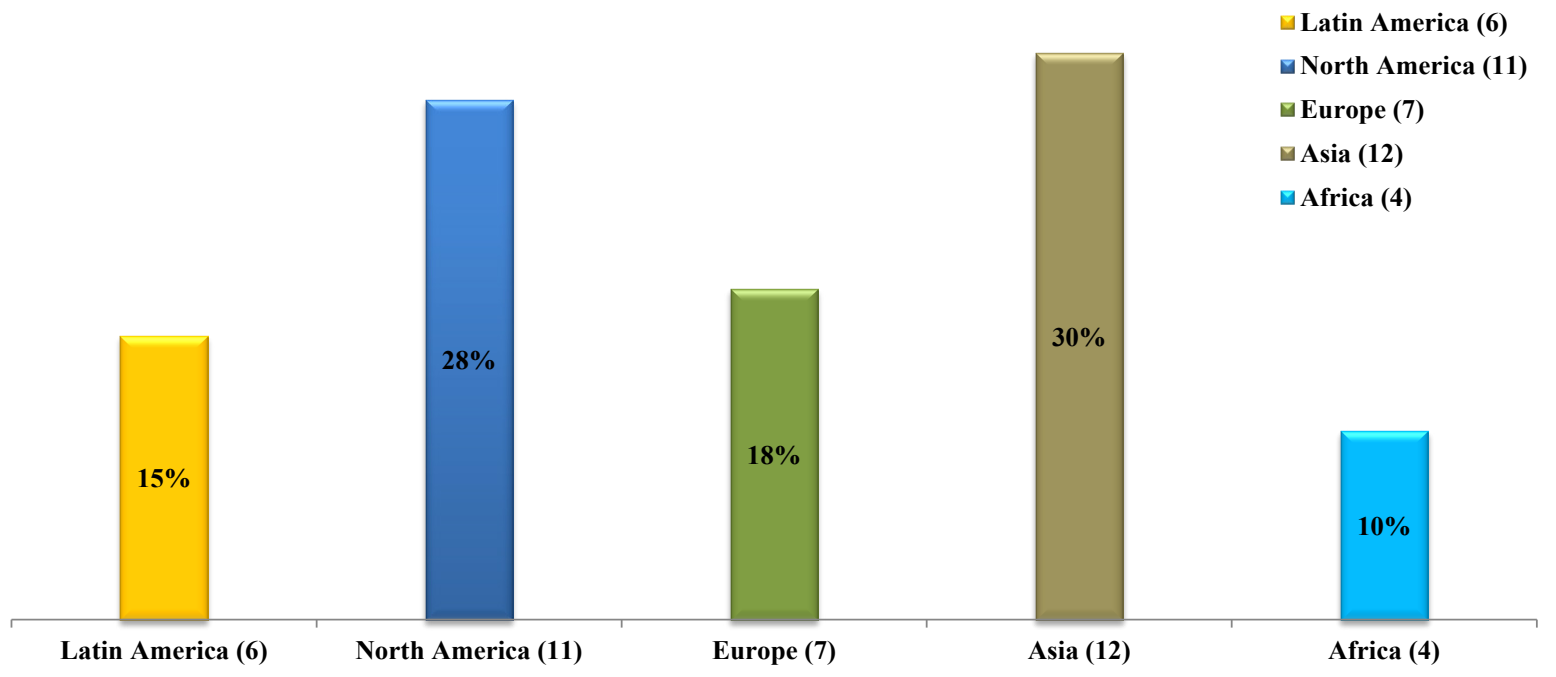

Figure 1: Distribution of articles as per region. 
Table 1: Relationship between preference by type of sampling and region.

\begin{tabular}{|c|c|c|c|c|c|c|c|c|}
\hline \multirow[t]{3}{*}{ Type of Sampling } & \multicolumn{6}{|c|}{ Region } & \multicolumn{2}{|c|}{ Chi-Square } \\
\hline & Latin America & North America & Europe & Asia & Africa & Sum & & \\
\hline & n (\%) & n (\%) & n (\%) & n (\%) & n (\%) & $\mathrm{N}(\%)$ & $\chi^{2}$ & $p$-value \\
\hline Statistical & $2(11.8)$ & $7(41.2)$ & $4(23.5)$ & $4(23.5)$ & $0(0.0)$ & $17(42.5)$ & \multirow[t]{3}{*}{6.201} & \multirow[t]{3}{*}{0.185} \\
\hline Convenience & $4(17.4)$ & $4(17.4)$ & $3(13.0)$ & $8(34.8)$ & $4(17.4)$ & $23(57.5)$ & & \\
\hline Sum & $6(15)$ & $11(28)$ & 7 (18) & $12(30)$ & $4(10)$ & $40(100.0)$ & & \\
\hline
\end{tabular}

convenience sampling was the most prevalent (57.5\%). This type of sampling was even more prevalent in studies from Latin America, Asia and Africa. Statistical sampling was the most preferred in North America and Europe (Table 1).

According to the Chi-Square test, there was no significant difference between the preferences for the type of sampling, that is, it can be affirmed with a $95 \%$ confidence level that the preference for the type of sampling does not depend on the region (Table 1).

\section{DISCUSSION}

The use of statistical sampling by the auditor in performing the audit tests may be appropriate in certain circumstances [22]. However, when using the inference process, it becomes very difficult to say with certainty that the sample taken from a given population represents exactly the same population [15]. This is because it is a sampling process and not a complete census. From this point, it is important that the auditor be aware of the fact that there may be sample errors leading him to draw wrong conclusions and constitute a risk to his work [23].

Populations in accounting audits differ from most other populations because, before the auditor begins testing, data has already been checked, accumulated, compiled, and summarized [24]. Rather than using sampling to quantitatively or qualitatively estimate the unknown, the auditor's objective is generally to corroborate the relative correctness of certain data such as balance of accounts or classes of transactions, or to assess adherence to internal control procedures in data processing [25].

Statistical sampling cannot and should not replace the auditor's judgment [26]. It requires, however, a high degree of judgment. Sampling tables are prepared for the purpose of supplying the auditor with sample sizes for known populations and use under specific circumstances. The choice of table depends on certain assumptions, including the auditor's decision on the level of confidence and accuracy desired.

In fact, statistical sampling techniques, while not replacing the auditor's judgment, help them form a judgment based on scientific methods, since their judgment becomes necessarily explicit when determining the precision and confidence to be employed in the statistical samples [27]. What is assumed is that knowledge of the procedures in this method, shows a structure that can help the auditor to plan their tests more effectively and efficiently [28].

As identified in this study, convenience sampling remains the most preferred by auditors. This technique is traditional, where the selection, amplitude and evaluation of the sample are based on an auditor's own criteria, and therefore, its nature is eminently subjective [5]. As the name implies, this approach relies heavily on the auditor's judgment for determining sample size and evaluating the sample's results [22]. The auditor develops this judgment for years of auditing in similar companies or even the same company [29]. The judgment of the auditors is often very good, however, for a given factual situation; two equally experienced auditors may come up with quite different sample sizes. The sample size for an auditor can sometimes be much larger than the sample size for another auditor. These differences in sample size are unexplained by the facts of the situation resulting solely from different judgment [22].

\section{CONCLUSIONS}

The use of statistical sampling does not relegate the auditor's judgment to the background but allows the risk of sampling to be measured. Through statistical tools, the auditor can specify the audit risk he or she wants to run, and the sample size is a reflection of that risk. Thus, statistical sampling can help the auditor: in the definition of efficient samples; in determining the size of the sample; and in the evaluation of the results obtained. However, these advantages are only obtained with additional costs related to the training of personnel, design of sampling plans and selection of items for evaluation, thus, non-statistical sampling is widely used by auditors, especially in testing small populations.

It can thus be concluded that both statistical sampling and nonstatistical sampling can provide sufficient and appropriate evidence to the auditor.

\section{AUTHORS' CONTRIBUTIONS}

FM conceptualized, designed, designed data collection methods and prepared the draft study proposal. FM prepared the manuscript, and IP, GC, EM and JU reviewed it. AV contributed to the proof-reading of the manuscript and screening the tittle and abstracts. All authors contributed to the reviewed draft version of the manuscript and approved the final version.

\section{COMPETING INTERESTS}

The authors have declared that no competing interests exist.

\section{ACKNOWLEDGEMENTS}

The Higher Institute of Accounting and Audit of Mozambique (ISCAM) and the Accounting Lecturer are recognized for providing resources for this research. To Dr. Julio Francisco Macuacua, Translator and Lecturer of English for correction of the English language.

\section{REFERENCES}

1. Souza LM, Souza M, Molinari M, Ramos A, Velloso BP. Brazilian public accounting: Integrative review. Int J Account Res. 2017;5:1-5.

2. Olukowade E, Balogun E () Relevance of forensic accounting in the detection and prevention of fraud in Nigeria. Hist Res Lett. 2015;23:17-25.

3. Vinson J, Robertson JC, Curtis MB. How auditors approach to client inquiry can affect audit quality: A mixed-method examination of client inquiry and note taking, SSRN's eLibrary. 2018;1-42. 
4. Hawkins E, Keune MB, Saunders KK. Can novice auditors be appropriate research participants? participant selection theory and survey evidence from interns, SSRN's eLibrary. 2016;1-56.

5. Australia CPA. Financial accounting and reporting. Int Account Stand Board. 2017;7:1-82.

6. Brasel A, Doxey K, Grenier MM, Reffett JH. Risk disclosure preceding negative outcomes: The effects of reporting critical audit matters on judgments of auditor liability. Account Rev. 2016;91:1345-1362.

7. Alles MA, Brennan M, Kogan G, Vasarhelyi A. Continuous monitoring of business process controls: A pilot implementation of a continuous auditing system at Siemens. In: Chan DY, Chiu V, Vasarhelyi MA (eds.), Continuous Auditing, Rutgers Studies in Accounting Analytics, Emerald Publishing Limited. 2018;219-246.

8. Vovchenko RA, Holina NG, Orobinskiy GM, Sichev AS. Ensuring financial stability of companies on the basis of international experience in construction of risks maps, internal control and audit. Eur Res Stud J. 2017;20:350-68

9. Donelson JM, Ege DC, McInnis MS. Internal control weaknesses and financial reporting fraud. Audit A J Pract Theory. 2016;36:45-69.

10. Jones P. Statistical sampling and risk analysis in auditing (1stedn), Routledge, London. 1999;1-182.

11. Appelbaum D, Nehmer RA. Designing and auditing accounting systems based on blockchain and distributed ledger principles. Feliciano Sch Bus. 2017;3:1-19.

12. Dimitrova J, Sorova A. The role of professional skepticism in financial statement audit and its appropriate appplication. J Econ. 2006;1:1-17.

13. Bailey LJ, Collins C, Abbott DL. The impact of enterprise risk management on the audit process: Evidence from audit fees and audit delay. Audit A J Pract Theory. 2017;37:25-46.

14. Raschke P, Saiewitz RL, Lennard A, Kachroo J. AI-enhanced audit inquiry: A research note. J Emerg Technol Account. 2018.

15. Mahaluça FA. Manual of Applied Statistics. 2016.

16. Sekaran R, Bougie. Research methods for business: A skill building approach, John Wiley \& Sons. 2016;1-448.

17. Askary NM, Arnaout S, Abughazaleh JPM. Audit evidences and modelling audit risk using goal programming. Int J Appl Decis Sci. 2018;11:18-35.

18. Nigrini MJ. Auditing using Benford's Law: A review of the literature with some new perspectives. J Emerg Technol Accounting. 2017;14:2946.

19. Swart JJ. Audit methodologies: developing an integrated planning model incorporating audit materiality, risk and sampling, (Doctoral Thesis), North-West Univ. 2018.

20. Yanti H, Hasnawati, Astuti C. Technical, moral competencies and communication skills for sustainability of accounting profession. Int J Sustain Dev. 2016;9:55-64.

21. Buchheit S, Doxey MM, Pollard T, Stinson SR. A technical guide to using amazon's mechanical turk in behavioral accounting research. Behav Res Account. 2018;30:111-122.

22. Elder J, Akresh RJ, Glover AD, Higgs SM, Liljegren JL. Audit sampling research: A synthesis and implications for future research. Audit J Pract Theory. 2013;32:92-129.

23. Jans MA, Alles M, Vasarhelyi MG. A field study on the use of process mining of event logs as an analytical procedure in auditing. Account Rev. 2014;89:1751-1773.

24. Dechow RG, Ge PM, Larson W, Sloan CR. Predicting material accounting misstatements. Contemp Account Resvol. 2011;28:170-182.

25. Sigauke N. Audit risk: An investigation into workload compression and materiality towards audit quality. Case study of Deloitte Zimbabwe-Harare office (Thesis), Faculty of Commerce, Department of Accounting, Midlands State University. 2013;1-60.

26. Vasarhelyi JP, Teeter MA, Krahel RA. Audit education and the realtime economy. Issues Account Educ. 2010;25:405-423.

27. Bell JB, Griffin TB. Commentary on auditing high-uncertainty fair value estimates. Audit A J Pract Theory. 2012;31:147-155.

28. Francis JR. A framework for understanding and researching audit quality. Audit A J Pract Theory. 2011;30:125-152.

29. Schultz E, Bierstaker JJ, O’Donnell JL. Integrating business risk into auditor judgment about the risk of material misstatement: The influence of a strategic-systems-audit approach. Acc Organ Soc. 2010;35:238-251. 